\title{
Studies on the Optimization of Lipase Production by Rhizopus sp. ZAC3 Isolated from the Contaminated Soil of a Palm Oil Processing Shed
}

\author{
Zainab Adenike Ayinla, Adedeji Nelson Ademakinwa, Femi Kayode Agboola* \\ Department of Biochemistry and Molecular Biology, Obafemi Awolowo University, Ile-Ife, Osun State, Nigeria.
}

\section{ARTICLE INFO}

Article history:

Received on: 05/12/2016

Accepted on: 17/01/2017

Available online: 20/03/2017

Key words:

Lipase, Rhizopus oryzae ZAC3, thermophilic fungi, ITS region, screening, optimization.

\begin{abstract}
This study investigated the screening, production and optimization of an extracellular lipase from a fungus isolated from the contaminated soil of a palm oil processing shed. This was with a view to obtaining a strain that can secrete lipase with biochemical properties exploitable for biotechnological applications such as bioremediation of oil contaminated sites. Soil samples were collected from palm oil contaminated sites in Gbogan, Osun State, Nigeria (Latitude N $7^{\circ} 29.1481^{\prime}$ and Longitude E $4^{\circ} 20.7587^{\prime}$ ). The isolated fungal strains were screened on tributyrin agar for exogenous lipolytic activity. Molecular identification was carried out by amplifications of ITS-1, 5.8S and ITS-2 regions. The effects of incubation time, inducers, $\mathrm{pH}$, temperature, carbon and nitrogen sources were varied for optimal lipase production using one factor at a time approach. Rhizopus oryzae ZAC3 (NCBI accession No: KX035094) was identified as the highest lipaseproducing strain. Maximum lipase production was observed on the fourth day, $\mathrm{pH} 5.0$ and a temperature of 45 ${ }^{\circ} \mathrm{C}$. Olive oil, xylose and yeast extract were the best inducer, carbon and nitrogen sources respectively for lipase production. There was a 2.02 fold increase in lipase production under these optimized conditions. In conclusion, Rhizopus oryzae ZAC3 lipase has properties exploitable for industrial and biotechnological applications.
\end{abstract}

\section{INTRODUCTION}

Lipases (triacylglycerol acylhydrolase, EC 3.1.1.3) catalyze the hydrolysis and synthesis of long-chain acylglycerols [1]. They catalyze the hydrolysis of triglycerides at the waterlipid interface and can also catalyze the reverse reaction (such as esterification and interesterification) in non-aqueous conditions, producing glycerides from glycerol and fatty acids [2, 3]. They are also involved in acidolysis, alcoholysis and aminolysis [4]. These reactions are of industrial applications in food processing, organic chemical processing, pharmaceuticals, cosmetics [5], paper manufacture, detergent formulations and in environmental management $[2,6]$. Microbial lipases are of wide interest because they are highly selective, stable and substrate specific [7]. The substrate and reaction specificities of lipases surpass those of any other known enzyme and the application potentials are limitless [8].

* Corresponding Author

Email:fkagbo@oauife.edu.ng
Currently, lipases have usage in biotechnology, single cell protein production, biosensor preparation, manufacture of pharmaceuticals and pesticides and in waste management [9]. These applications are linked to the potential of lipases to catalyze both hydrolytic and synthetic reactions. In addition to their extremely high versatility, they also possess unique properties such as regioselectivity, chemoselectivity, stereoselectivity, nonrequirement of cofactors and stability in organic solvent [10]. Microbial lipases vary, depending on the strain of the organism, growth medium composition, $\mathrm{pH}$, temperature, carbon and nitrogen sources [11-12].

They possess technical and economic advantages when cultivated in medium containing appropriate nutrient composition under controlled conditions [13]. Among the microbial sources of lipase, fungi are preferred for industrial applications. If the enzyme is produced extracellularly, then further purification becomes easier [14]. Rhizopus, Candida, Pseudomonas, Mucor and Geotrichum sp. stand out as the major commercially viable strains [15]. 
Lipase activity has been detected in various species of Rhizopus such as Rhizopus oryzae [16-17], Rhizopus oligosporus [18-19], Rhizopus japonicus [20], Rhizopus delemar [21] and Rhizopus homothallicus [10]. In recent years, remarkable work has been done to engineer microorganisms to exhibit unique and appropriate features for industrial processes. Thus screening of microorganisms with lipolytic activities in extreme habitats could aid the discovery of novel lipases. This is the first report of this lipase-producing mould from a palm oil contaminated soil, although there have been reports on lipases produced by fungi from palm oil mill effluent (POME) [22-25]. This study will provide information on a microbial organism which can secrete lipase for industrial purposes. Furthermore, the molecular identification of the strain that secretes this enzyme can be manipulated to expedite large scale enzyme production. The enzyme, as well as the mould, can also be used for bioremediation of palm oil contaminated areas. Hence, we describe an optimized fermentation process for the enhanced production of an extracellular lipase from a thermophilic Rhizopus oryzae strain ZAC3 isolated from palm oil contaminated sites in Majapa Community Palm Oil Processing Shed (Latitude N 7²9.1481' and Longitude E $4^{\circ} 20.7587$ ), Gbongan, Osun State, Nigeria.

\section{MATERIALS AND METHODS}

\subsection{Reagents and Media}

Gum arabic, p-nitrophenyl laurate, Triton X-100, glyceryl tributyrate, malt extract agar and tributyrin agar were purchased from Sigma-Aldrich (USA). Qiagen DNA Mini Kit and ITS 4 and ITS 5 primers were obtained from Qiagen, Valencia, USA. All other chemicals used in this study were of analytical grade and of high purity.

\subsection{Methods}

\subsubsection{Isolation and Screening of Lipase Producers}

Three different soil samples were collected from palm oil contaminated sites in Majapa Community Palm Oil Processing Shed (Latitude N 7²9.1481' and Longitude E 4²0.7587'), Gbongan, Osun State, Nigeria. The samples were collected in sterile cellophane bags. Serial dilution was carried out with subsequent plating on Malt Extract Agar amended with $0.01 \%$ streptomycin to inhibit bacterial growth. Several subculturing was carried out until pure colonies were obtained and these were subsequently maintained on agar slants at $4{ }^{\circ} \mathrm{C}$ until needed for further use. The isolated fungi were screened for lipase production using tributyrin agar by analyzing the formation of clear zones around colonies according to the method of Freire [26] and Colen et al. [27]. A small fraction of each strain was inoculated in petri dishes containing $2 \% \mathrm{w} / \mathrm{v}$ tributyrin agar (peptone $5 \mathrm{~g} / \mathrm{L}$, yeast extract $3 \mathrm{~g} / \mathrm{L}$, agar $12 \mathrm{~g} / \mathrm{L}$ ) and $1 \%$ tributyrin and incubated at 37 ${ }^{\circ} \mathrm{C}$ for $96 \mathrm{~h}$. The lipolytic activities of all isolates were then compared by measuring the width of the areas of clearing. Strains that showed lipolytic halo radius $(\mathrm{R}) /$ colony radius ( $\mathrm{r}$ ) ratio greater than 2.0 were selected. The basal medium used for initial lipase production contained the following $(\mathrm{g} / 100 \mathrm{ml})$ : peptone (0.3), yeast extract (0.1), gum arabic (0.1), $\mathrm{NaCl}(0.05)$, $\mathrm{CaCl}_{2} .2 \mathrm{H}_{2} \mathrm{O}$ (0.05), olive oil (1), pH 7.0. A $250 \mathrm{ml}$ Erlenmeyer flask containing $50 \mathrm{ml}$ of culture medium was inoculated with an 8 $\mathrm{mm}$ diameter disc of actively growing fungal mycelium. The inoculated flasks were then incubated at room temperature with constant shaking for $96 \mathrm{~h}$. Extracellular enzyme was harvested by centrifugation at $5,000 \mathrm{rpm}$ for $15 \mathrm{~min}$ at $4{ }^{\circ} \mathrm{C}$ and the clear supernatant being the enzyme source was used to determine lipase activity.

\subsubsection{Identification of the Lipase-Producing Fungi}

2.2.2.1 Identification Using Morphological and Cultural Characteristics

The several fungal isolates were observed for their growth characteristics (texture, pigmentation, form, spore formation) and morphologically through a staining technique using Lactophenol-in-cotton blue stain (for moulds) and gram-staining (for yeasts). The prepared slides were examined under light microscope. Biochemical differentiation of the yeasts was carried out by sugar fermentation test.

\subsubsection{Identification using Molecular Methods}

The isolated strain with high lipase activity was identified using molecular methods at the International Institute of Tropical Agriculture (IITA), Ibadan, Oyo State, Nigeria. This was carried out by amplification and sequencing of the Internal Transcribed Spacer (ITS) region of the nuclear ribosomal DNA. The evolutionary status and species of the strain was determined through sequence similarity analysis and construction of phylogenetic tree.

\subsubsection{Fungal Genomic DNA extraction and Polymerase Chain} Reaction (PCR conditions)

Briefly, total genomic deoxyribonucleic acid (DNA) was extracted using a Qiagen DNA Mini Kit (Qiagen, Valencia, CA) according to manufacturer's instructions. The reaction mixture for the PCR contained approximately $20 \mathrm{ng}$ template genomic DNA, PCR buffer (0.05M KCl, 0.01M Tris $\mathrm{HCl}$ pH 9.0, 0.1\% Triton-X), $2.5 \mathrm{mM} \mathrm{MgCl}_{2}, 200 \mu \mathrm{M}$ dNTPs, $1.0 \mathrm{U}$ of Taq DNA polymerase, $400 \mu \mathrm{M}$ of each primer (forward primer ITS 5 GGAAGTAAAAGTCGTAACAAGG, reverse primer ITS 4 TCCTCCGCTTATTGATATGC) and sterile distilled water to make up to $50 \mu \mathrm{l}$ of reaction mixture [28 - 29]. PCR profile was programmed at $94^{\circ} \mathrm{C}$ for 1 min denaturation followed by primer annealing at $35^{\circ} \mathrm{C}$ for $1 \mathrm{~min}$ and primer extension at $72^{\circ} \mathrm{C}$ for 2 min with a total of 40 cycles. The initial denaturation of DNA was for $2 \mathrm{~min}$ at $94^{\circ} \mathrm{C}$. The final extension period was adjusted for 5 min at $72^{\circ} \mathrm{C}$, then $3 \mu \mathrm{L}$ of $6 \mathrm{x}$ loading buffer was added to each tube. The PCR products were analyzed on $1 \%$ agarose gel.

\subsection{Sequence Alignment and Phylogenetic Tree Construction}

The amplified products were sequenced with a big dye terminator kit from PE/ABI using the reverse ITS-4 primer. The 
ITS sequences were compared to those available in the GenBank database (http://www.ncbi.nlm.nih.gov/BLAST/) using the BLASTN search. Sequence alignment was carried out using Clustal X while the phylogenetic tree was constructed using the neighbour joining method with the bioinformatics software, MEGA version 8.0. The sequences were deposited in the NCBI database with accession number KX 035094.

\subsubsection{Lipase Assay}

Lipase activity was assayed spectrophotometrically using p-nitrophenyl laurate (p-NPL) according to the method of Vorderwulbecke et al. [30] with slight modification. Briefly, the emulsion was prepared by mixing $1 \mathrm{ml}$ of isopropanol containing $0.001 \mathrm{~g}$ of pNPL with $9 \mathrm{ml}$ of $0.05 \mathrm{M}$ Tris-HCl buffer $(\mathrm{pH} 7.5)$ containing $50 \mu \mathrm{l}$ Triton X-100 and $0.01 \mathrm{~g}$ gum arabic. A total of $700 \mu \mathrm{l}$ of the freshly prepared substrate solution was mixed with $300 \mu \mathrm{l}$ of the appropriately diluted enzyme solution. The liberated p-nitrophenol was monitored by the change in absorbance at 410 $\mathrm{nm}$ at an interval of $15 \mathrm{~s}$ over a $3 \mathrm{~min}$ period using a spectrophotometer. One unit of enzyme activity is defined as the amount of enzyme that released $1 \mu \mathrm{mol}$ of $\mathrm{p}$-nitrophenol from $\mathrm{p}$ NPL in one minute under the assay conditions.

\subsubsection{Optimization of Lipase Production}

Optimization of different nutrient and physical parameters for lipase production were studied by maintaining all factors constant except the one being studied. The effect of incubation time (days), inducers (olive oil, palm oil, groundnut oil, coconut oil), $\mathrm{pH}(4-9)$, temperature $\left(25-65^{\circ} \mathrm{C}\right)$, various carbon sources (glucose, galactose, xylose, maltose, lactose, sucrose), and nitrogen sources (peptone, beef extract, yeast extract, tryptone, $\left.\mathrm{NaNO}_{3},\left(\mathrm{NH}_{4}\right)_{2} \mathrm{SO}_{4}\right)$ were varied for optimal lipase production. Shaking conditions for each parameter was carried out in a rotary orbital shaker.

\subsubsection{Effect of Incubation Period on Lipase Production}

The effect of incubation period on lipase production was determined by varying the incubation time. Fifty millilitres of sterilized culture medium was inoculated with an $8 \mathrm{~mm}$ diameter disc of fungal mycelium and incubated for seven days at $30{ }^{\circ} \mathrm{C}$ and at neutral $\mathrm{pH}$ with constant agitation at $150 \mathrm{rpm}$ in an incubator shaker. Two millilitres was withdrawn every $24 \mathrm{~h}$ and assayed for lipase activity.

\subsubsection{Effect of Inducers on Lipase Production}

The effect of inducers was studied by substituting olive oil with different oils (1\%): palm oil, groundnut oil and coconut oil while other components of the media were kept constant.

\subsubsection{Determination of Optimum $\mathrm{pH}$ on Lipase Production}

The optimum $\mathrm{pH}$ for the production of lipase was determined by varying the $\mathrm{pH}$ of the basal medium from 4.0 to 9.0 prior to inoculation and incubation for $96 \mathrm{~h}$ at $30{ }^{\circ} \mathrm{C}$ with agitation at $150 \mathrm{rpm}$ in an incubator shaker. The supernatants were centrifuged at $5000 \mathrm{rpm}$ at $4{ }^{\circ} \mathrm{C}$ for $15 \mathrm{~min}$ and assayed for lipase activity.

\subsubsection{Effect of Temperature on Lipase Production}

The optimum temperature for lipase production was determined by incubating the isolate in the basal medium at $25{ }^{\circ} \mathrm{C}$, $35{ }^{\circ} \mathrm{C}, 45{ }^{\circ} \mathrm{C}, 55{ }^{\circ} \mathrm{C}$ and $65{ }^{\circ} \mathrm{C}$ with constant agitation. The supernatants obtained were assayed for lipase activity and evaluated within these parameters.

\subsubsection{Effect of Carbon Source on Lipase Production}

The effect of different carbon sources on the production of lipase was studied; different carbon sources such as maltose, glucose, galactose, xylose, lactose and sucrose were studied. They were supplemented separately to the medium at a concentration of $1 \% \mathrm{w} / \mathrm{v}$. This was followed by inoculation and incubation for $96 \mathrm{~h}$ at $30{ }^{\circ} \mathrm{C}$ with steady agitation.

\subsubsection{Effect of Nitrogen Source on Lipase Production}

Different nitrogen sources such as ammonium sulphate, ammonium nitrate, tryptone, yeast extract, peptone and beef extract were supplemented in the production medium. All the media were previously adjusted to $\mathrm{pH} 7.0$ followed by inoculation and incubation for $96 \mathrm{~h}$ at $30{ }^{\circ} \mathrm{C}$ with steady agitation at $150 \mathrm{rpm}$. The supernatants were centrifuged at $5,000 \mathrm{rpm}$ at $4{ }^{\circ} \mathrm{C}$ for $15 \mathrm{~min}$ and assayed for lipase activity.

\subsubsection{Biomass Dry Weight Determination}

Fungal biomass from crude enzyme was determined according to dry weight. A pre-weighted filter paper was used to filter the growth media containing the mycelia followed by drying in an incubator at $37{ }^{\circ} \mathrm{C}$ for $4 \mathrm{~h}$.

\section{RESULTS AND DISCUSSION}

Out of the thirteen (13) pure fungal isolates obtained following repeated subculturing on Malt Extract Agar (MEA), seven (7) of these pure isolates showed varying magnitudes of clear zones on tributyrin agar, indicating the presence of degradation reaction of tributyrin by extracellular enzymes, inducing lipase production. The isolates were further tested for lipolytic activity in the culture broth using p-nitrophenyl laurate as substrate (Table 1).

Table 1 Extracellular lipolytic activity in the basal medium by the selected isolates.

\begin{tabular}{ccc}
\hline Isolate number & Fungal Strain & Lipase Activity (U/ml) \\
\hline A3 & Aureobasidium pullulans & 9.59 \\
B4 & Trichoderma sp. & 16.15 \\
C3 & Rhizopus oryzae & 16.84 \\
C5 & Candida pseudotropicalis & 15.28 \\
C6 & Aspergillus glaucus & 15.94 \\
C8 & Mucor mucedo & 12.82 \\
C9 & Scopulariopsis brevicaulis & 12.22 \\
\hline
\end{tabular}

One unit of enzyme activity was defined as the amount of enzyme that released $1 \mu \mathrm{mol}$ of p-nitrophenol from p-NPL in one minute under the assay conditions. 
Rhizopus oryzae, Trichoderma sp., Aspergillus glaucus, Candida pseudotropicalis, Mucor mucedo, Scopulariopsis brevicaulis, Aureobasidium pullulans from the contaminated soil showed potential for lipase production. The result confirms that majority of the strains were potent enough to produce lipase and also gives an indication that lipolytic moulds and yeast are widespread in the chosen palm oil contaminated environment. Rhizopus oryzae has been reported to produce lipase with high activity by Salleh et al. [31], Essamri et al. [32], Hiol et al. [16], Ghorbel et al. [17] and Mukhtar et al. [33]. Studies have also revealed that Trichoderma sp. are good lipase producers. Musa and Adebayo-Tayo [34] showed that lipase production by Trichoderma virens, T. stromaticum, T. longibrachiatum, T. ressei reached $19.80 \mathrm{U} / \mathrm{ml}, 19.15 \mathrm{U} / \mathrm{ml}, 17.10 \mathrm{U} / \mathrm{ml}$ and $10.60 \mathrm{U} / \mathrm{ml}$ respectively. Also, lipases have previously been obtained from the genus Aspergillus as reported by Adinarayana et al. [35] and Cihangir and Sarikaya [36]; from Candida sp. as reported by Bigey et al. [37]; from Mucor mucedo by Stern et al. [38] and Mucor sp. by Abbas et al. [39]; from Scopulariopsis brevicaulis by Nagy et al. [40] which was able to resolve racemic 1-phenylethanol rac-1a and racemic 1-cyclohexylethanol rac-1b displaying its biocatalytic activity and enantiomer selectivity; and from Aureobasidium pullulans by Leathers et al. [41]. As shown in Table 1, Strain C3 (Rhizopus oryzae) had the highest lipase activity. Based on this, genetic characterization and optimization of cultural conditions were restricted to the most active strain (C3). The identity of Isolate C3 was confirmed by comparison of the ITS1-5.8S-ITS2 region sequences obtained from the isolate with the sequences available in the GenBank database. Situated between the Small SubUnit-coding sequence (SSU) and the Large SubUnit-coding sequence (LSU) of the ribosomal operon are the ITS1 and ITS2 sequences surrounding the $5.8 \mathrm{~S}$-coding sequence. These sequences are highly variable and can only be aligned with confidence when closely related taxa are being compared [28]. Approximately 400 bp sequences were obtained and aligned with other sequences available in the database, and a phylogenetic tree (Fig. 1) was constructed to determine the evolutionary status of the strain.

The ITS sequences of strain C3 were highly homologous (80 \%) with the sequence of Rhizopus oryzae (NCBI accession number FJ478087.1). Based on this, strain C3 was assigned to oryzae species of Rhizopus genus and named Rhizopus oryzae ZAC3. The sequence of strain ZAC3 ITS domain is available in NCBI database (accession number KX 035094).

Optimization of culture parameters is one of the best strategies for enhancing microbial enzyme production and is often achieved by studying the production medium composition [1]. According to Ooijkaas et al. [42], with recent technological advancement, appropriate nutrients and optimal concentrations can be established after the initial formulation of the medium. In the present study, the classical OFAT (One Factor at a Time) method was used to optimize process variables.

In lipase biosynthesis, incubation time plays a pivotal role. An incubation period of 4 days under submerged fermentation was found to be optimum for enhanced lipase production by Rhizopus oryzae ZAC3. As incubation period advanced, lipase production also increased, reaching its maximal value of $15.60 \mathrm{U} / \mathrm{ml}$ at $1.13 \mathrm{~g} / \mathrm{L}$ mycelial dry weight on day 4 (Fig, 2).

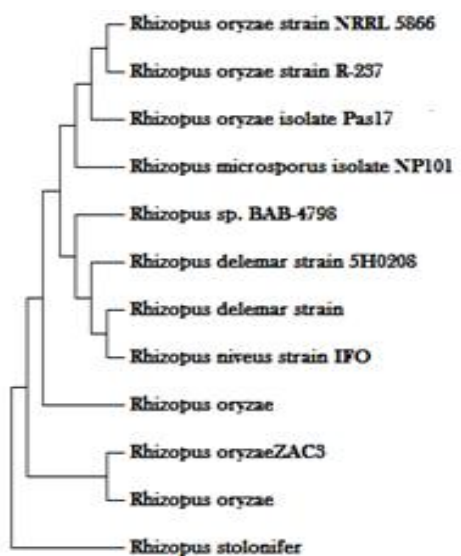

Fig. 1: Neighbour joining phylogenetic tree based on ITS1-5.8S-ITS2 sequences showing relationship between strain ZAC3 and other related strains. This was drawn using the bioinformatics software MEGA version 8.0 after aligning of the sequence with Clustal X.

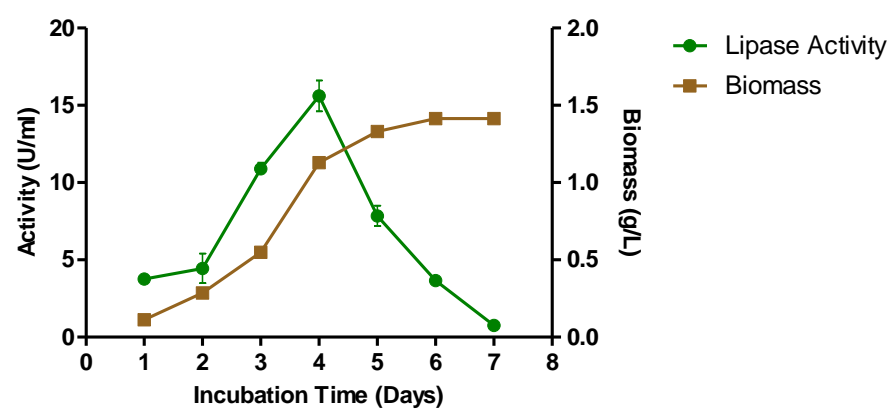

Fig. 2: Effect of different incubation periods on lipase and biomass production by Rhizopus oryzae ZAC3 under unoptimized conditions (neutral $\mathrm{pH}$ and $30^{\circ} \mathrm{C}$ ). Samples were removed at different intervals and assayed for lipase activity and growth simultaneously.

Afterwards, lipase activity gradually declined as the incubation period increased further. Increase in biomass was seen up to 5 days before entering into the stationary phase and simultaneously enzyme activity was also decreasing. According to Diaz et al. [10] such effect may likely be due to the fungus secreting proteases that can cleave and inactivate the lipase. Different incubation periods are required by different fungi for optimum lipase production. Similar incubation time of 4 days was reported for maximum lipase activity in Fusarium solani FS1 by Maia et al. [43], in Rhizopus arrhizus by Yang et al. [44], in Penicillium notatum by Rehman et al. [45] , in Ganoderma lucidum by Amin et al. [46] and in Emericella nidulans NFCCI 3643 by Lanka et al. [25]. However, an incubation time of 3 days was reported for maximal lipase production in Rhizopus chinensis [47] and Aspergillus niger MTCC 2594 [48]. Hence, the optimum incubation period was maintained throughout the study.

Microbial lipases mostly are inducible. Upon induction, they secrete extracellular enzymes into the surrounding environment. Such inducible extracellular lipases are produced in 
the presence of inducers such as fatty acids, oils, triacylglycerol, tween, bile salts and glycerol [44] although the requirement for sugar as a carbon source in addition to lipids varies with the microorganism. Inducers in the form of lipid substrates (olive oil, palmoil, groundnut oil and coconut oil) were studied for their effects on lipase production by Rhizopus oryzae ZAC3. Our findings showed that olive oil induced highest lipase production when compared with other vegetable oils (Fig. 3).

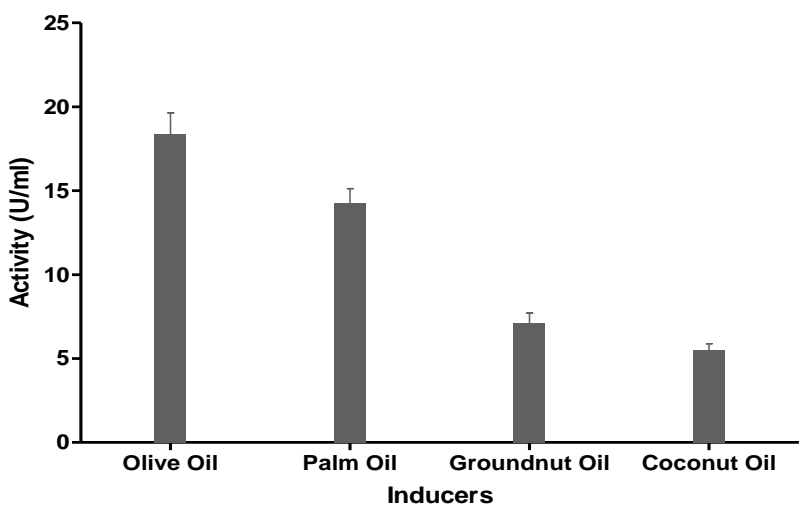

Fig. 3: Effect of different inducers on lipase production by Rhizopus oryzae ZAC3

According to Nunes et al. [49] and Papanikolaou et al. [50], among different vegetable oils, olive oil is considered as the best inducer of lipase production. The result, to some extent, also correlates with the findings by Lakshmi et al. [51] that lipase production increases with relative increase of C18:n fatty acid esters in the respective vegetable oils, with olive oil having the highest percentage composition of C18:n fatty acid and coconut oil having the least [52]. Our results revealed olive oil as the highest lipase inducer and coconut oil as the lowest inducer of lipase production (Fig. 3). This was in agreement with Zouaoui et al. [53] who reported olive oil as the best lipase inducer in Pseudomonas aeruginosa and also correlates with the findings by Benjamin and Pandey [54] who showed that Candida rugosa lipase production was proportionally increased with the increase in concentration of olive oil and maximum production was achieved at $10 \%(\mathrm{v} / \mathrm{v})$ olive oil concentration. Enzyme production with relatively high activity is possible only after optimizing growth parameters. Optimization of the various nutritional and physical parameters is known to significantly increase product yield, as culture environment is known to have a dramatic influence on enzyme production [55]. By providing the suitable cultural conditions, yield of the enzyme can be enhanced several folds. About 2.02fold increase in lipase production was achieved in basal medium optimized with yeast extract $(1 \%)$, xylose $(1 \%)$, olive oil $(1 \%)$, $\mathrm{pH} 5.0$, incubated at $45{ }^{\circ} \mathrm{C}$ for 4 days. Initial $\mathrm{pH}$ is one factor which significantly influences extracellular enzyme production. The effect of $\mathrm{pH}$ on lipase activity was determined in basal medium adjusted to different $\mathrm{pH}$ values ranging from 4 to 9 . In this study, we report an acidic $\mathrm{pH}$ of 5.0 to be the optimum and most appropriate for lipase production by Rhizopus oryzae ZAC3 (Fig. 4). No growth was observed at pH 9.0. Reports show that most lipases produced by fungi occur under acidic conditions as majority of researchers have reported an acidic $\mathrm{pH}$ as the optimum for enzyme production by various fungi. Most fungal cultures prefer a slightly acidic $\mathrm{pH}$ medium for growth and enzyme biosynthesis [56] which is in agreement with the result obtained in this study. According to Shulter and Kargi [57], change in $\mathrm{pH}$ value may alter the three-dimensional structure of the enzyme. Salleh et al. [29] and Essamri et al. [30] independently reported an optimum $\mathrm{pH}$ of 5 for lipase production by $R$. oryzae and R.oryzae (ATCC 24563) respectively. On the other hand, Kader et al. [58] reported an optimum $\mathrm{pH}$ of 6.0 for Rhizopus MR12 while Nahas [18] and Diaz et al. [10] reported pH 6.5 as being optimum for lipase production by $R$. origosporus and $R$. homothallicus.

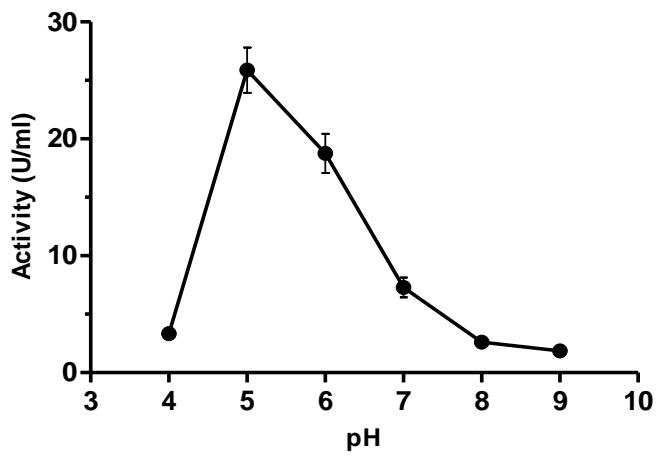

Fig. 4: Effect of pH on lipase production by Rhizopus oryzae ZAC3.

It has been discovered that incubation temperature is a significant controlling factor for enzyme production and increase in temperature tends to favour fungal growth to some extent [59]. In general, the temperature required for lipase production corresponds with the growth conditions of the microorganism [1]. Most lipase producing organisms grow in moderate temperature between 25 and $40{ }^{\circ} \mathrm{C}$, making them mesophilic in nature. Optimum temperature for lipase production by Rhizopus oryzae ZAC3 was observed at $45{ }^{\circ} \mathrm{C}$ when incubated at different temperatures ranging from 25 to $65^{\circ} \mathrm{C}$ as shown in Figure 5 .

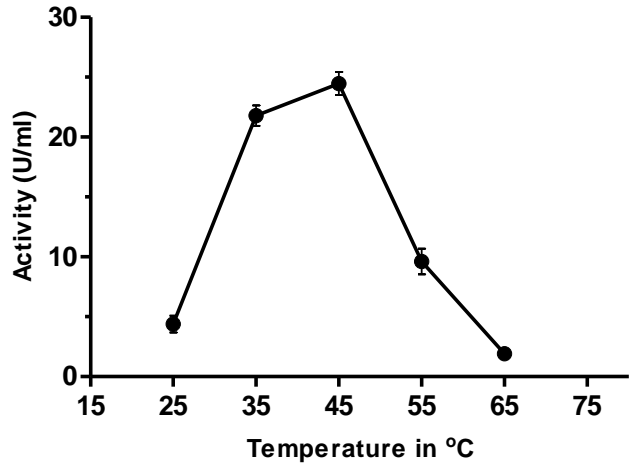

Fig. 5: Effect of temperature on lipase production by Rhizopus oryzae ZAC3.

Beyond this temperature, enzymatic activity decreased rapidly. No fungal growth was observed at $65{ }^{\circ} \mathrm{C}$. The optimum temperature obtained in this study is comparable to that previously reported for extracellular lipase from the thermophilic $R$. oryzae by 
Salleh et al. [29] who also reported an optimum temperature of 45 ${ }^{\circ} \mathrm{C}$. Our isolate, being thermophilic, showed average growth and activity even at a high temperature of $55{ }^{\circ} \mathrm{C}$. This $R$. oryzae can be classified as thermophilic as described by Edwards [60] because it can grow at a temperature above $50{ }^{\circ} \mathrm{C}$ in liquid media. According to Fariha et al. [61], thermophiles hydrolyse lipids with better efficiency than mesophiles. This greater efficiency in the hydrolysis of oils is because there is increased reactant mobility, increased miscibility of the lipids and other hydrophobic substrates in water and also because higher temperatures hasten reaction rates [62]. Rhizopus MR12 [56] and Rhizopus strain JK-1 [53] both produced lipase optimally at $30{ }^{\circ} \mathrm{C}$. Both medium $\mathrm{pH}$ and temperature affect microbial lipase fermentations. Our isolate Rhizopus oryzae ZAC3 can grow in the $\mathrm{pH}$ range of $4.0-8.0$ and temperature range of $25-55^{\circ} \mathrm{C}$. Maximum enzyme production was obtained at $45{ }^{\circ} \mathrm{C}$, although the culture was able to grow even at a higher temperature of $55{ }^{\circ} \mathrm{C}$ while still retaining some considerable activity. Lipase activity and growth was also observed at $35{ }^{\circ} \mathrm{C}$. No visible growth was observed at $65{ }^{\circ} \mathrm{C}$. The effect of carbon sources on the production of lipase by $R$. oryzae ZAC3 was tested by using maltose, glucose, galactose, xylose, lactose and sucrose at an amount of $1 \%$. The requirement for sugar as a carbon source in addition to lipids varies with the microorganism as carbon sources serve as important substrates for energy production [1]. Among the tested carbon sources, xylose was observed to be the best, giving an activity of $23.33 \mathrm{U} / \mathrm{ml}$ (Fig. 6 ) and this was followed closely by lactose. Lactose was reported as best carbon source for lipase production by Rhizopus MR12 [56], glucose as best carbon source for Rhizopus JK-1 [53] and dextrose as best for Pseudomonas aeruginosa [51].

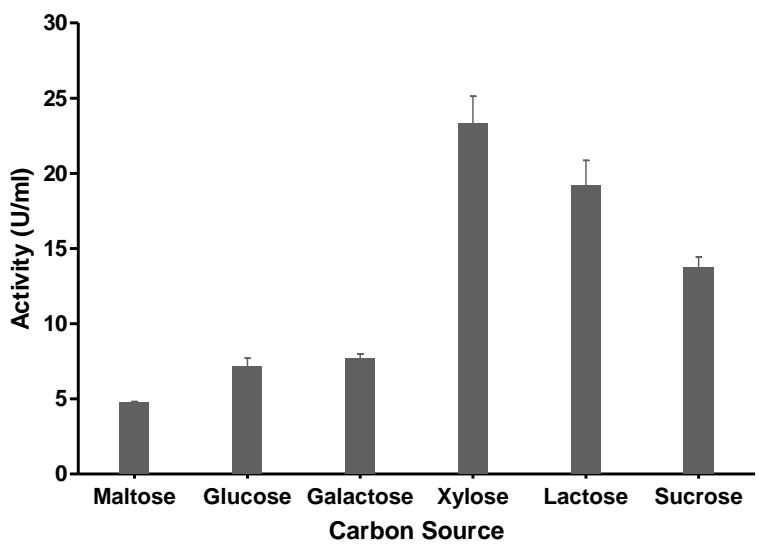

Fig. 6: Effect of carbon source on lipase production by Rhizopus oryzae ZAC3.

Among the various organic and inorganic nitrogen sources tested, maximum lipase production $(29.43 \mathrm{U} / \mathrm{ml})$ was observed with yeast extract (Fig. 7). Both organic and inorganic nitrogen sources have been traditionally used for lipase production. Inorganic nitrogen source in the form of ammonium sulphate $\left(\left(\mathrm{NH}_{4}\right)_{2} \mathrm{SO}_{4}\right)$ and sodium nitrate $\left(\mathrm{NaNO}_{3}\right)$ failed to significantly support lipase production by our fungi as they did with Rhodotorula glutinis [63] and Burkholderia cepacia ATCC 25416 [64] respectively. Rajendran and Thangavelu [65] found that both peptone and yeast extract were required by $R$. arrhizus for lipase production. Our results clearly indicate that organic nitrogen sources were preferred by $R$. oryzae ZAC3 to inorganic ones for lipase production.

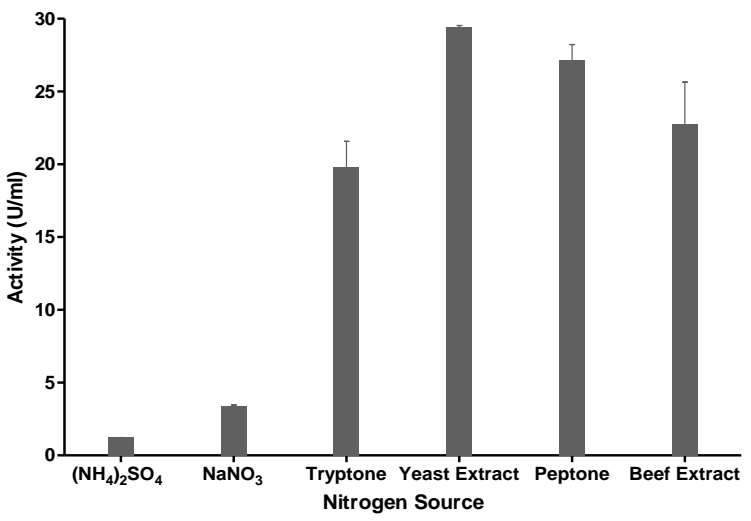

Fig. 7: Effect of nitrogen source on lipase production by Rhizopus oryzae ZAC3

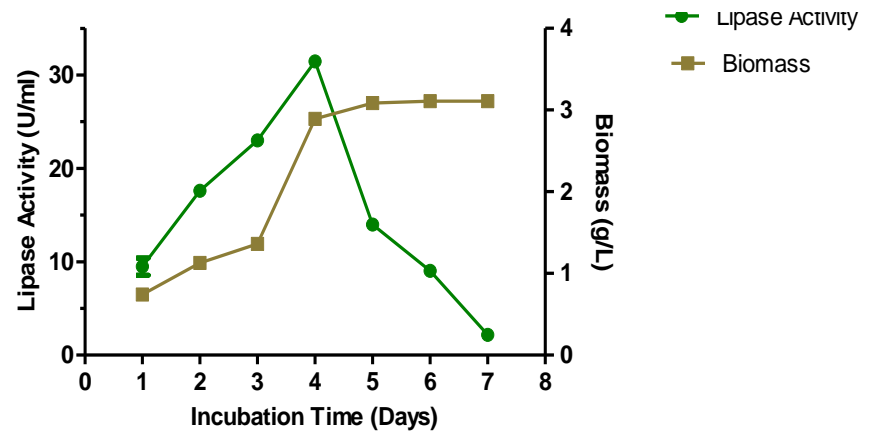

Fig. 8: Lipase and biomass production by Rhizopus oryzae ZAC3 under optimized culture conditions.

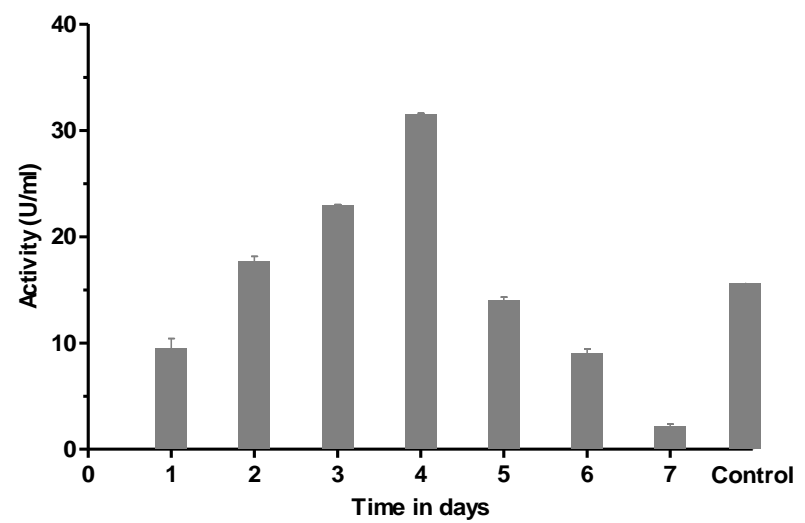

Fig. 9: Lipase production at optimized conditions $\left(45^{\circ} \mathrm{C}, \mathrm{pH} 5.0\right.$ in basal medium with xylose and yeast extract). Samples were removed at different intervals and assayed for activity. Basal medium without carbon and nitrogen source, at neutral $\mathrm{pH}$, was considered as control.

Under optimized culture conditions (1\% xylose and $1 \%$ yeast extract), fungal lipase formation reached its maximum value with an activity of $31.46 \mathrm{U} / \mathrm{ml}$ at $2.61 \mathrm{~g} / \mathrm{L}$ mycelia dry weight within $96 \mathrm{~h}$ of cultivation at $45{ }^{\circ} \mathrm{C}$ with $\mathrm{pH}$ maintained at 5.0 (Fig. 8), which corresponds to an increase of about 2.02 fold in lipase production (from 15.60 to $31.46 \mathrm{U} / \mathrm{ml}$ ) when compared with the control which is the same basal medium without the optimum 
parameters (Fig. 9). Biomass increase was seen up to 6 days before entering into the stationary phase with enzyme activity also simultaneously decreasing. The short incubation time and high temperature for lipase production offers biotechnological exploitation of this organism.

\section{CONCLUSION}

An inducible lipase that is stable at acidic conditions and high temperature was isolated and it was observed that culture conditions greatly influenced lipase production and optimization of these culture parameters improved lipase production. The organism (Rhizopus oryzae ZAC3) can be biotechnologically exploited for commercialization due to its unique features. Presently, the enzyme is being purified and will be extensively characterized. After these preliminary studies, further work in this field aims to overexpress the lipase gene and increase the production of lipase in the strain so that the activity can compare well with that of strains used for commercial production, while still retaining its unique features.

\section{ACKNOWLEDGMENTS}

The authors, F. K. A and Z. A. A are grateful to the Research Committee of the Obafemi Awolowo University (OAU), Ile-Ife for the TETFUND Grant (Grant No: DVC/AC/37/ TETFUND/RP/2014/3) used for this study.

Conflict of Interests: There are no conflicts of interest.

\section{REFERENCES}

1. Salihu A, Alam MZ. Production and applications of microbial lipases: A review. Scientific Research and Essays. 2012; 7(30):26672677.

2. Sharma R, Chisti Y, Banerjee UC. Production, purification, characterization, and applications of lipases. Biotechnology Advances. 2001; 19:627- 662.

3. Saxena RK, Sheoran A, Giri B, Davidson WS. Purification strategies for microbial lipases. Journal of Microbiological Methods. 2003; 52:1-18.

4. Savitha J, Srividya S, Jagat R. Identification of potential fungal strain(s) for the production of inducible, extracellular and alkalophilic lipase. African Journal of Biotechnology. 2007; 6(5):564-568

5. Laachari F, El Bergadi F, Sayari A, Elabed S, Mohammed I, Harchali $\mathrm{EH}$, Ibnsouda SK Biochemical characterization of a new thermostable lipase from Bacillus pumilus strain. Turkish Journal of Biochemistry. 2015; 40(1):8-14.

6. Jaeger K, Eggert T. Lipases for biotechnology. Current Opinion in Biotechnology. 2002; 13: 390-397.

7. Treichel H, Oliveira DD, Mazuti MA, Luccio MD, Oliveira JV. A review on microbial lipases production. Food Bioprocess Technology. 2010; 3:182-196.

8. Gandhi NN. Applications of Lipases. Journal of the American Oil Chemists' Society. 1997; 74(6): 621-634.

9. Vakhlu J, Kour A. Yeast lipases: Enzyme purification, biochemical properties and gene cloning. Electronic Journal of Biotechnology. 2006; 9 (1):15.

10. Diaz JCM, Rodriguez JA, Roussos S, Cordova J, Abousalham A, Carriere F. Lipase from the thermotolerant fungus Rhizopus homothallicus is more thermostable when produced using solid state fermentation than liquid fermentation procedures. Enzyme and Microbial Technology. 2006; 39(5):1042-1050.

11. Gupta R, Gupta N, Rathi P. Bacterial lipases: An overview of production, purification and biochemical properties. Applied Microbiology and Biotechnology. 2004; 64:763-781.

12. Souissi N, Bougatef A, Triki-ellouz Y, Nasri M. Production of lipase and biomass by Staphylococcus simulans grown on sardinella (Sardinella aurita) hydrolysates and peptone. African Journal of Biotechnology. 2009; 8(3):451-457.

13. Srivastava ML. Fermentation Technology, Alpha Science, Oxford. United Kingdom, 2008; pp. 404.

14. Rapp P, Backhaus S. Formation of extracellular lipases by filamentous fungi, yeasts and bacteria. Enzyme and Microbial Technology. 1992; 14(11):938-981.

15. Ertugrul S, Donmez G, Takac S. Isolation of lipase producing Bacillus sp. from olive mill wastewater and improving its enzyme activity. Journal of Hazardous Materials. 2007; 149:720-724.

16. Hiol A, Jonzo M, Rugani N, Druet D, Sarda L, Comeau L. Purification and characterization of an extracellular lipase from a thermophilic Rhizopus oryzae strain isolated from palm fruit. Enzyme and Microbial Technology. 2000; 26(5-6):421-430.

17. Ghorbel S, Souissi N, Triki-Ellouz Y, Dufosse L, Guerard F, Nasri M. Preparation and testing of Sardiella protein hydrolysates as nitrogen source for extracellular lipase production by Rhizopus oryzae. World Journal of Microbiology and Biotechnology. 2005; 21(1):33-38.

18. Nahas E. Control of lipase production by Rhizopus oligosporus under various growth conditions. Journal of General Microbiology. 1988; 134:227-233.

19. Iftikhar T, Niaz M, Afzal M, Haq IU, Rajoka MI. Maximization of intracellular lipase production in a lipase-overproducing mutant derivative of Rhizopus oligosporus DGM 31: a kinetic study. Food Technology and Biotechnology. 2008; 46(4):402-412.

20. Aisaka K, Terada O. Purification and properties of lipase from Rhizopus japonicus. Journal of Biochemistry. 1981; 89(3):817-822.

21. Iwai M, Tsujisaka Y. The purification and the properties of the three kinds of lipase from Rhizopus delemar. Agricultural Biology and Chemistry 1974; 38:1241-1247.

22. Salihu A, Alam MZ, AbdulKarim MI, Salleh HM. Optimization of lipase production by Candida cylindracea in palm oil mill effluent based medium using statistical experimental design. Journal of Molecular Catalysis B: Enzymatic. 2011; 69(1):66-73.

23. Nwuche CO, Aoyagi H, Ogbonna JC. Lipase production from palm oil mill effluent by Aspergillus terreus immobilized on Luffa sponge. Journal of Applied Sciences. 2013; 13:5661-5671.

24. Asih DR, Alam MZ, Salleh MN Salihu A. Pilot-scale production of lipase using palm oil mill effluent as a basal medium and its immobilization by selected materials. Journal of Oleo Science. 2014; 63(8):779-785.

25. Lanka S, Pydipalli M, Latha JNL. Optimization of Process Variables for Extracellular Lipase Production from Emericella nidulans NFCCI 3643 Isolated from Palm Oil Mill Effluent (POME) Dump Sites Using OFAT Method. Research Journal of Microbiology. 2015; $10(2): 38-53$

26. Freire DM, Teles EMF, Bom EPS, Sant'Anna JrGL. Lipase production by Penicillium restrictum in a bench-scale fermenter: effect of carbon and nitrogen nutrition agitation and aeration. Applied Biochemistry and Biotechnology. 1997; 63-65:409-421.

27. Colen G, Junqueira RG, Moraes-Santos T. Isolation and screening of alkaline lipase production fungi from Brazil savanna soil. World Journal of Microbial Biotechnology. 2005; 22(8):881-885.

28. White TJ, Bruns T, Lee S, Taylor J. Amplification and direct sequencing of fungal ribosomal RNA genes for phylogenetics, 1990 , pp. 315-322. In MA Innis, DH Gelfand, JJ Sninsky, TJWhite (ed.). PCR protocols: a guide to methods and applications. Academic Press, Inc., New York, N.Y.

29. Ademakinwa AN, Agboola FK. Biochemical characterization and kinetic studies on a purified yellow laccase from newly isolated Aureobasidium pullulans NAC8 obtained from soil containing 
decayed plant matter. Journal of Genetic Engineering and Biotechnology. 2016; http://dx.doi.org/10.1016/j.jgeb.2016.05.004.

30. Vorderwulbecke T, Kieslich K, Erdmann H. Comparison of lipases by different assays. Enzyme Miicrobiology Technology. 1992; 14:632-639.

31. Salleh AB, Musani R, Razak CNA. Extra and intracellular lipases from a thermophilic Rhizopus oryzae and factors affecting their production. Canadian Journal of Microbiology. 1993; 39 (10):978981.

32. Essamri M, Deyris V, Comeau L. Optimization of lipase production by Rhizopus oryzae and study on the stability of lipase activity in organic solvents. Journal of Biotechnology. 1998; 60:97-103.

33. Mukhtar H, Khursheed S, Ul-Haq I, Mumtaz MW, Rashid U, AlResayes SI. Optimization of Lipase Biosynthesis from Rhizopus oryzae for Biodiesel Production Using Multiple Oils. Chemical Engineering Technology. 2016; 39:1-10.

34. Musa H, Adebayo-Tayo BC. Screening of microorganisms isolated from different environmental samples for extracellular lipase production. Assumption University. Journal of Technology. 2012;15(3):179-186.

35. Adinarayana K, Raju NB, Zargar MI, Devi RB Lakshmi PJ, Ellaiah $P$. Optimization of process parameters for production of lipase in solid-state fermentation by newly isolated Aspergillus species. Indian Journal of Biotechnology. 2004; 3:65-69.

36. Cihangir N, Sarikaya E. Investigation of lipase production by a new isolate of Aspergillus sp. World Journal of Microbiology and Biotechnology. 2004; 20(2):193-197.

37. Bigey F, Tuery K, Bougard D, Nicaud J, Moulin G. Identification of triacylglycerol lipase gene family in Candida deformans: Molecular cloning and functional expression. Yeast. 2003; 20(3):233-248.

38. Stern AM, Ordal ZJ, Halvorson HO. Utilization of fatty acids by and lipolytic activities of Mucor mucedo. Journal of Bacteriology. 1953; 68(1):24-27.

39. Abbas H, Hiol A, Deyris V, Comeau L. Isolation and Characterization of an extracellular lipase from Mucor sp strain isolated from palm fruit. Enzyme and Microbial Technology. 2002; 31(7):968-975.

40. Nagy V, Toke ER, Keong LC, Szatzker G, Ibrahim D, Omar IC, Szakacs G, Poppe L. Kinetic resolutions with novel, highly enantioselective fungal lipases produced by solid state fermentation. Journal of Molecular Catalysis B: Enzymatic. 2006; 39:141-148.

41. Leathers TD, Rich JO, Anderson AM, Manitchotpisit P. Lipase production by diverse phylogenetic clades of Aureobasidium pullulans. Biotechnology Letters. 2013; 35(10):1701-1706.

42. Ooijkaas LP, Weber FJ, Buitelaar RM, Tramper J, Rinzema A. Defined media and inert supports: Their potential as solid-state fermentation production systems. Trends in Biotechnology. 2000; 18:356-360

43. Maia MMD, Heasley A, Morais MMC, Melo EHM, Morais Jr MA, Ledingham WM, Filho JLL. Effect of culture conditions on lipase production by Fusarium solani in batch fermentation. Bioresource Technology. 2001; 76:23-27.

44. Yang X, Wang B, Cui F, Tan T. Production of lipase by repeated batch fermentation with immobilized Rhizopus arrhizus. Process Biochemistry. 2005; 40:2095-2103.

45. Rehman S, Bhatti HN, Bhatti IA, Asgher M. Optimization of process parameters for enhanced production of lipase by Penicillium notatum using agricultural wastes. African Journal of Biotechnology. 2011; 10(84):19580-19589.

46. Amin F, Bhatti HN, Rehman S. Optimization of growth parameters for lipase production by Ganoderma lucidum using response surface methodology. African Journal of Biotechnology. 2011; 10(28):55145523.

47. Sun SY, Xu Y, Solid-state fermentation for 'whole-cell synthetic lipase' production from Rhizopus chinensis and identification of the functional enzyme. Process Biochemistry. 2008;4:219-224.

48. Edwinoliver NG, Thirunavukarasu K, Naidu RB, Gowthaman MK, Kambe TN, Kamini NR. Scale up of a novel tri-substrate fermentation for enhanced production of Aspergillus niger lipase for tallow hydrolysis. Bioresource Technology. 2010; 101:6791-6796.

49. Nunes PA, Pires-Cabral P, Guillen M, Valero F, Luna D, FerreiraDias S. Production of MLM-Type structured lipids catalyzed by immobilized heterologous Rhizopus oryzae lipase. Journal of the American Oil Chemists' Society. 2011; 88:473-480.

50. Papanikolaou S, Dimou A, Fakas S, Diamantopoulou P, Philippoussis A, Galiotou-Panayotou M, Aggelis G. Biotechnological conversion of waste cooking olive oil into lipid-rich biomass using Aspergillus and Penicillium strains. Journal of Applied Mirobiology. 2011; 110:1138-1150.

51. Lakshmi BS, Kangueane P, Abraham B, Pennathur G. Effect of vegetable oils in the secretion of lipase from Candida rugosa (DSM 2031). Letters in Applied Microbiology. 1999; 29:66-70.

52. Knothe G, Dunn, RO, Bagby MO. Biodiesel: The use of vegetable oils and their derivatives as alternative diesel fuels. In: Saha B.C., Woodward, J. (Eds.), Fuels and Chemicals from Biomass, ACS symposium series 666, Washington, DC (Chapter 10); 1997.

53. Zouaoui B, Bouziane A, Ghalem BR. Production, Optimization and Purification of Lipase from Pseudomonas aeruginosa. African Journal of Microbiology. 2012; 6(20):4417-4423.

54. Benjamin S, Pandey A. Optimization of Liquid media for lipase production by Candida rugosa. Bioresource Technology. 1996; 55:167-170.

55. Kantak JB, Bagade AV, Mahajan SA, Pawar SP, Shouche YS, Prabhune AA. Isolation, Identification and Optimization of a New Extracellular Lipase producing Strain of Rhizopus sp. Applied Biochemistry and Biotechnology. 2011; 164(7):969-978.

56. Haltrich D, Nidetzky B, Kulbe KD, Steiner W, Zupancic S. Production of fungal xylanases. Bioresource Technology. 1996; 58:137-161.

57. Shulter ML, Kargi F. Bioprocess Engineering Basic Concept, Prentice Hall of India Pvt Ltd, New Delhi, India; 2000.

58. Kader R, Yousuf A, Hoq MM. Optimization of lipase production by a Rhizopus MR12 in shake culture. Journal of Applied Sciences. 2007; 7(6): 855-866.

59. Norouzian D. Effect of different factors on fermentative production of enzymes by fungi. Dynamic Biochemistry, Process Biotechnology and Molecular Biology. 2008; 2(1):14-18.

60. Edwards C. "Thermophiles". In Microbiology of extreme environments. Edited by C. Edwards. McGraw-Hill Publishing Co., New York. 1990; pp. 1-33.

61. Fariha H, Aamer AS, Abdul H. Industrial applications of microbial lipases. Enzyme and Microbial Technology. 2006;39:235-251.

62. Saranya P, Kumari HS, Rao BP, Sekaran G. Lipase production from a novel thermo-tolerant and extreme acidophile Bacillus pumilus using palm oil as the substrate and treatment of palm oil-containing wastewater. Environmental Science and Pollution Research. 2014; 21:3907-3919.

63. Papaparaskevas D, Christakopoulos P, Kekos D, Macris BJ. Optimizing production of extracellular lipase from Rhodotorula glutinis. Biotechnology Letters. 1992; 14:397-402.

64. Bueno PRM, Ferreira de Oliveira T, Caliari M, Castiglioni GL, Soares Junior MS. Selection and Optimization of extracellular lipase production using Agro industrial waste. African Journal of Biotechnology. 2014; 13(4):566-573.

65. Rajendran A, Thangavelu V. Statistical experimental design for evaluation of medium components for lipase production by Rhizopus arrhizus MTCC 2233. LWT-Food Science and Technology. 2009; 42:985-992.

\section{How to cite this article:}

Ayinla ZA, Ademakinwa AN, Agboola FK. Studies on the Optimization of Lipase Production by Rhizopus sp. ZAC3 Isolated from the Contaminated Soil of a Palm Oil Processing Shed. J App Biol Biotech. 2017; 5 (02): 030-037. 